\title{
A história encastelada e o ensino encurralado: reflexões sobre a formação docente dos professores de história ${ }^{1}$
}

\section{The history "encastled" and the teaching cornered: reflections on the teacher training of history teachers}

\author{
Erinaldo Vicente Cavalcanti*
}

\begin{abstract}
RESUMO
A Lei 13.415/2017 extinguiu a obrigatoriedade do ensino de História no ensino médio. Por conseguinte, mais uma vez colocou em suspensão a História como ciência. O presente artigo propõe-se a fazer uma reflexão sobre algumas características da História como ciência e sua relação com o ensino. Em seguida, as reflexões são direcionadas para analisar as Matrizes Curriculares dos Cursos de Licenciatura em História nas universidades federais do Nordeste do Brasil como uma opção para problematizar a História como ciência, como lugar de saber/poder e como espaço de formação de professores. Almeja, portanto, ampliar o debate sobre a formação docente e direciona a análise, de forma específica, para as questões acerca do ensino de História e do livro didático como principal instrumento de trabalho dos docentes da educação básica.
\end{abstract}

Palavras-chave: Ciência Histórica. Ensino de História. Formação Docente.

\begin{abstract}
The federal law 13.415/2017 has extinguished the obligation of History's Teaching in High School. Therefore, it has, once again, suspended History as a science. The present article proposes to reflect on some characteristics of History as a Science and its relation with Teaching. Next, the reflections
\end{abstract}

1 Gostaria de agradecer às críticas e sugestões apontadas pelos membros pesquisadores do iTemnрo quando o texto foi debatido em nossos encontros.

* Universidade Federal do Sul e Sudeste do Pará. Marabá, Pará, Brasil. E-mail: ericontadordehistorias@gmail.com. https://orcid.org/0000-0002-9912-5713. 
are directed to analyze the Curricular Matrices of the History's degree courses in the Federal Universities of the Northeast of Brazil as an option to problematize History as a Science, as a place of knowledge/power and as a space for teacher training. So, it seeks to broaden the debate on teacher's formation and direct the analysis, in a specific way, to the questions about Teaching History and the history's manuals as the main tool for the teachers of Basic Education.

Keywords: History. Teaching of History. Teacher Training.

A história como uma matéria a ser ensinada e aprendida tem de passar por um exame didático referente à sua aplicabilidade de orientar para a vida. (Jörn Rüsen)

\section{Considerações iniciais}

A Educação Básica e o ensino de História, em especial, foram mais uma vez violados. A Lei n. ${ }^{0} 13.415$, de 16 de fevereiro de 2017, colocou mais uma vez a História em suspeição quando retirou a obrigatoriedade do seu ensino nos currículos do ensino médio no Brasil. Fica estabelecido, com esse dispositivo, que ficará a cargo dos sistemas de ensino a oferta de mais de um itinerário formativo além daqueles que compõem os itinerários obrigatórios com as disciplinas de Língua Portuguesa, Matemática, Arte, Filosofia, Sociologia e Língua Inglesa. De acordo com o texto dessa lei, "os sistemas de ensino, mediante disponibilidade de vagas na rede, possibilitarão ao aluno concluinte do ensino médio cursar mais um itinerário formativo" (Lei 13.415/2017). ${ }^{2}$

Utilizo a Lei n. ${ }^{\circ} 13.415 / 2017$ como um sintoma, ou um indício para analisar uma questão-problema bastante complexa, qual seja o modelo de ciência histórica praticado nas universidades por meio do qual se promove a formação

2 “Art. 36. O currículo do ensino médio será composto pela Base Nacional Comum Curricular e por itinerários formativos, que deverão ser organizados por meio da oferta de diferentes arranjos curriculares, conforme a relevância para o contexto local e a possibilidade dos sistemas de ensino, a saber: I - linguagens e suas tecnologias; II - matemática e suas tecnologias; III - ciências da natureza e suas tecnologias; IV - ciências humanas e sociais aplicadas; V - formação técnica e profissional”. [E sentencia]: "§ $1^{\circ} \mathrm{A}$ organização das áreas de que trata o caput e das respectivas competências e habilidades será feita de acordo com critérios estabelecidos em cada sistema de ensino". Lei 13.415. Disponível em: <http://www.planalto.gov.br/ccivil_03/_ato2015-2018/2017/ Lei/L13415.htm>. Acesso em: 30 mar. 2017 (Grifos meus). 
de inúmeros professores e professoras. Nesse sentido, o artigo propõe-se a fazer uma reflexão sobre a História como ciência e seu ensino frente às relações de forças que se desenham nos dias atuais, e, por conseguinte, refletir sobre os desafios e as possibilidades que se apresentam em um cenário ambientado por dúvidas, inquietações e incertezas. Em seguida, as reflexões são direcionadas para analisar as Matrizes Curriculares dos Cursos de Licenciatura em História nas universidades federais do Nordeste do Brasil como uma opção para problematizar a História como ciência, como lugar de saber/poder e como espaço de formação de professores. De maneira específica, deseja ampliar o debate sobre a formação docente e concentra a análise nas questões acerca do ensino de História e do livro didático como principal instrumento de trabalho dos docentes da educação básica.

A Medida Provisória n. ${ }^{\circ}$ 746, de 2016 - que foi posteriormente transformada na Lei n. $^{\circ}$ 13.415/2017 - estimulou o debate. Alguns segmentos sociais ligados ao ensino e representantes parlamentares ${ }^{3}$ posicionaram-se contra essa Medida Provisória e criticaram as mudanças inseridas no currículo do ensino médio. A Associação Nacional de História (Anpuh/Brasil, 2015) fez petição pública em seu site para colher assinaturas contra essa proposta. ${ }^{4}$ Entretanto essas ações não produziram eco, ou ao menos não reverberaram como força capaz de tencionar as relações de poder nas quais a História, como área do conhecimento e disciplina escolar, encontra-se imersa. São ações que não conseguem pressionar as relações de força no sentido de criar um campo de possibilidade capaz de redimensionar os rumos dos projetos atuais. Nesse sentido, a História como campo de conhecimento, como ciência, depara-se com um grande desafio. Como produzir força e construir legitimidade fora dos muros das universidades? Como produzir reconhecimento e defender sua importância para além do público restrito de historiadores? Como construir discursos e práticas que sejam capazes de defender a validade e a permanência do seu ensino no currículo do ensino médio?

Nessa dimensão, parece que a História se encontra entrincheirada, encurralada dentro dos departamentos das universidades, sem conseguir força e

3 Na Câmara dos Deputados, a Medida Provisória no 746/2016 obteve 263 votos favoráveis e 106 contra. Na configuração das bancadas partidárias, o Partido dos Trabalhadores (PT) e o Partido Comunista do Brasil ( $\mathrm{PC}$ do B) apresentaram o maior percentual de votos contrários. Entre os que votaram a favor, se destacam o Partido do Movimento Democrático Brasileiro (PMDB), o Partido da Social Democracia Brasileira (PSDB) e o Democratas (DEM). Para visualizar a relação completa dos parlamentares e seus respectivos votos, consultar $<$ http://congressoemfoco.uol.com. br/noticias/reforma-do-ensino-medio-veja-como-cada-deputado-votou/>. Acesso em: 30 mar. 2017.

4 Disponível em: $<$ http://site.anpuh.org/index.php/2015-01-20-00-01-55/noticias2/noticias-destaque/item/4032-contra-a-exclusao-da-historia-como-disciplina-obrigatoria-no-ensino-medio>. Acesso em: 10 mar. 2017. 
apoio fora desses espaços. Talvez a falta de força e apoio resida exatamente em virtude de a História ter permanecido, em larga medida, encastelada dentro das universidades.

\section{A "mestra da vida" encastelada?}

A metáfora do encastelamento da História aplica-se, aqui, em duas dimensões específicas. O termo "encastelar", como verbo intransitivo que pode ser, é sinônimo de "encerrar-se". Do meu ponto de vista, não seria inverossímil dizer que, pela maneira como a ciência histórica vem sendo praticada em nossas universidades, ela se encontra, em certa medida, encastelada dentro dos departamentos, sem conseguir estabelecer vínculos com os problemas da vida prática e cotidiana do cidadão.

Em certas dimensões, é como se a História feita pelos historiadores - ou por uma parte deles - estivesse sendo produzida apenas para ser consumida dentro de seu próprio castelo; feita, pensada e direcionada para atender às demandas internas da academia, como se fosse uma produção voltada apenas para aqueles que recebem o codinome de historiador, vivendo em seus castelos, pesquisando, publicando e falando para si mesmos. Quase que um discurso endógeno, ou um discurso para seus próprios convertidos.

O outro significado da metáfora está intimamente ligado a essa dimensão: encastelada pela maneira em que se constitui, qual seja, separada, distante e estrangeira a uma parte significativa dos anseios dos segmentos sociais, dos problemas e das demandas da vida ordinária de homens e mulheres que não habitam o castelo. Esse encastelamento certamente contribuiu para que o ensino da História se encontre, em certas dimensões, encurralado, limitado a um espaço pequeno e anêmico. Um encastelamento que concorreu para que o ensino ficasse como uma plebe sem território e alçado a um espaço de pouca representatividade, promovendo, por conseguinte, a asfixia que vem sofrendo 5 .

A questão é: o que promove o encastelamento da ciência histórica, e, por extensão, o seu distanciamento das questões ligadas à vida cotidiana na

5 Por outro lado, há de se considerar, na produção historiográfica, as demandas oriundas dos grupos sociais que adentraram a academia, impulsionando o campo histórico acadêmico a se rever, como negros, grupos LGBTs, movimentos feministas, identitários, luta pelos direitos humanos que tensionaram e tensionam a produção histórica. Essas questões que se desdobram em diferentes sentidos, projetos e ações como mestrados, teses ou cursos de formação para professores e sinalizam mudanças, cuja exequibilidade irá demonstrar suas direções e raio de alcance. 
sociedade, estabelecendo uma espécie de divórcio entre a História pesquisada, explicada e produzida pelos historiadores e os demais segmentos sociais?

Paul Ricœur, no seu texto O passado tinha um futuro, levanta essa discussão e nos ajuda a pensar essas e outras questões. Ele indaga o que promove a hostilidade em relação ao ensino de História, ou pelo menos o que a torna tão tensa e suspeita. Em seguida, levanta as seguintes questões:

Como ligar o ensino de história à preocupação com o presente e com o futuro que os adolescentes podem experimentar? Essas questões colocam-se na realidade porque a história, aquela que os historiadores contam e tentam explicar e interpretar, parece estrangeira ao que os homens fazem e experimentam (RICEUR, 2012, p. 369).

As problematizações levantadas por Paul Ricœur nos colocam frente a um complexo universo de questões, a começar pelo título de seu artigo. Quais questionamentos esse título pode nos provocar? Comecemos pela expressão verbal que ele usou para se referir ao tempo, sendo ele um teórico estudioso das relações constitutivas das experiências temporais: "tinha". Ou seja, ele afirma que, outrora, em um "tempo passado", ou em um "passado presente", existia um futuro. Não se trata de profecia, nem de prever o que existiria ou não no tempo futuro. Pelo contrário. Trata-se de entender a dimensão presente do tempo, compreender suas relações de força e entender as condições de possibilidades de sua existência. Em outras palavras, trata-se de um questionamento delicado e bastante erudito que levanta a possibilidade de questionar nosso experimento de tempo denominado presente e, dessa forma, entender que a ciência histórica pode estar com seu futuro comprometido, ou que suas práticas não estão contribuindo para seu prolongamento no tempo.

Os historiadores - ou uma parte deles - conhecem, mas parecem ignorar um dos principais fundamentos de sua área de atuação: toda experiência é temporal, incluindo a existência da História como Ciência. A história dessa área do conhecimento demonstra que ela não existe desde o sempre nem continuará existindo por toda a eternidade. A História como ciência, como área de conhecimento, não é infinita, nem perene. Se uma parte dos historiadores conhece essa condição, parece, todavia, não demonstrar interesse por algumas questões que podem contribuir para abreviar a existência da vida da História no tempo.

Uma das forças que atribui sentido e significado à História é seu ensino. Independentemente da pesquisa que desenvolvemos, da temática que estudamos, da instituição em que atuamos, somos professores atuando na docência 
e tendo o ensino como parte obrigatória e principal de nossa profissão. Afinal, nós, professores formadores, fazemos concurso para professor do magistério superior. Se o ensino é o espaço de atuação de todo professor, por que o ensino da própria História não desperta o interesse em muitos departamentos de História das universidades no Brasil, mesmo que circule um discurso que tenta elevar e enaltecer o ensino? Tenta, apenas ${ }^{6}$.

Como apontam as pesquisas de Margarida Oliveira e Itamar Freitas (2013) e Claudia Ricci (2015) a formação docente do professor de história tem sido pautada predominante nos departamentos de Educação. As próprias diretrizes que normatizam os cursos de graduação em história expressam a ausência e a omissão no que tange aos fundamentos voltados à formação do professor de história, conforme apontado por Selva Guimarães Fonseca (2008).

Esse cenário expressa-se nas grandes universidades espalhadas pelo Brasil, como demonstram Marieta de Moraes e Renato Franco. Esses autores ressaltam que, mesmo diante de inúmeros debates e avanços, sobretudo após a aprovação da Lei n. ${ }^{\circ}$ 9.394, de 20 de dezembro de 1996 (Lei de Diretrizes e Bases da Educação Nacional [LDB]):

Na enorme maioria dos cursos de licenciatura em história persiste a valorização do pesquisador em detrimento do professor e a separação entre a academia e ensino. Nas Universidades de maior prestígio, espaço em que deveríamos encontrar professores qualificados para exercer o magistério, frequentemente nos deparamos com a resistência dos docentes às discussões sobre o ensino da disciplina. (MORAES; FRANCO, 2008, p. 89).

Nessa dimensão, o debate não é sobre priorizar a formação docente e o ensino, em detrimento da pesquisa, como se essas dimensões fossem antinômicas. A reflexão é direcionada no sentido de problematizar a necessidade de trazer para o centro do interesse da ciência histórica o universo de questões ligadas ao ensino e à formação docente. Demonstrar, por conseguinte, a importância de apreender o ensino e a formação do professor como objeto de pesquisa da História como ciência, por entender que essas dimensões se constituem em forças potenciais para o reconhecimento e a legitimidade da própria História.

Isso implica reconhecer a necessidade (urgente) de reconfigurar o currículo de História, de repensar as Matrizes Curriculares dos cursos de História e, por

6 É oportuno destacar as ações dos GTs de ensino de História espalhados pelas seções estaduais da Anpuh e as ações da Associação Nacional dos Pesquisadores em Ensino de História (Anpeh). 
conseguinte, da educação básica. Implica reconhecer que a História apreendida, aprendida e ensinada nas universidades não está respondendo às necessidades de estabelecer as conexões entre as demandas do tempo presente e de constituir-se como ciência.

Sabemos que o currículo é um campo de intensa batalha política. É um espaço de lutas e enfrentamentos. É um território de disputas, na interpretação de Miguel Arroyo (2010), por exemplo. É lugar de disputas de projetos políticos e sociais, como defendem Moreira e Silva (2007); um espaço de invenção, criação e representação do mundo como atestam Carmem Teresa Gabriel e Ana Maria Monteiro (2014). Ou seja, o currículo não é apenas lugar de disputas por seleção de conteúdos e metodologias de ensino. $\mathrm{O}$ "currículo é uma opção cultural, um projeto seletivo de cultura, uma seleção cultural de determinados grupos." (FONSECA, 2008, p. 118).

Como mostram as pesquisas da professora Claudia Ricci, as questões que envolvem a nova legislação para os cursos de licenciatura em História, a reformulação do currículo e as atividades concretas em sala de aula parecem "[...] colocar a política de formação de professores ainda como uma questão não resolvida no interior das universidades. As soluções encontradas parecem continuar vinculadas ao engajamento pessoal, e não institucional, dos professores universitários envolvidos nesta questão." (RICCI, 2015, p. 129).

A questão levantada por Ricœur continua em aberto. Como conectar a História produzida na academia de modo a estabelecer conexões com a vida cotidiana dos jovens estudantes de História? Como ressaltou o estudioso, esse hiato existe, sobretudo, porque a História experienciada pelos historiadores continua estrangeira - para usar suas palavras como empréstimo - à vida que os homens vivenciam. Esse distanciamento é parte constituinte do próprio processo de construção da História como ciência, como também assinalou Ricœur.

Nesse movimento, as questões ligadas aos processos de aprendizagem do conhecimento histórico perderam relevância na oficina da História e foram deixadas de lado no processo de "cientifização" da História. O processo que transformou a História em ciência, de acordo com Rüsen:

[...] excluiu da competência da reflexão histórica racional aquelas dimensões do pensamento histórico inseparavelmente combinadas com a vida prática. Desse ponto de vista, pode ser dito que a história científica, apesar de seu clamor racional, havia conduzido aquilo que eu gostaria de chamar "irracionalização" da história (RÜSEN, 2011, p. 25). 
Entretanto, mesmo sendo sinalizado por alguns historiadores, parece que o ensino continua a ser visto, apropriado e representado como algo de pouca importância para a legitimidade da História. Para uma parcela de historiadores que atua como professor do magistério superior, é como se o reconhecimento e a importância de sua área de atuação em nada precisassem do ensino, como já ressaltado anteriormente.

Parece-me ser esse o alerta que Ricœur faz ao usar, no título do seu artigo, o verbo "ter" conjugado no tempo pretérito, por meio da expressão "tinha", e assim sentenciar que o "passado tinha um futuro". Nessa dimensão, ele problematiza a estranheza da História praticada na academia com a vida cotidiana dos jovens estudantes e argumenta que "[...] esse distanciamento da história com relação à vida é, na verdade, constitutivo do conhecimento histórico." (RICEEUR, 2012, p. 370). Ou seja, a História - ou uma parte dela - escrita, pesquisada e explicada pelos historiadores parece alheia, demasiado longínqua da vida dos homens.

Entretanto reconhecer a existência do distanciamento não basta. Saber que ele faz parte do próprio processo de constituição da História como ciência não é suficiente. Com esse modelo de História praticado nas universidades, por meio do qual se vem formando gerações de professores e professoras, como esperar que os docentes da educação básica tenham interesse pelo ensino? Como desejar que eles valorizem a dimensão do ensino na área da História, quando sua grande maioria foi formada em cursos de licenciatura cuja Matriz Curricular relegou a uma ou duas disciplinas a responsabilidade para problematizar todo o universo que envolve o ensino? Como esperar que os professores formados em nossas universidades - formados por nós, professores/formadores - promovam uma interpretação envolvente, cativante, de forma sedutora e politicamente engajada do ensino, se uma grande parte dos professores formadores tende a ignorar a dimensão do ensino na formação dos professores de História?

Nessa dimensão, Margarida Oliveira e Itamar Freitas ressaltam que, entre os profissionais da área, existe a constatação de que “[...] há algum tempo 'alguma coisa parece estar fora de ordem', mas não temos clareza de que coisa é essa e, o pior, não assumimos a responsabilidade sobre o enfrentamento desses problemas." (OLIVEIRA; FREITAS, 2013, p. 132). Esses autores questionam como formar formadores sensíveis ao trabalho de ensinar história, destacando que "[...] um grande desafio imposto aos responsáveis pelos cursos de formação inicial em história é a formação dos formadores." (OLIVEIRA; FREITAS, 2013, p. 137).

Por conseguinte, como esperar que os jovens, na educação básica, valorizem o ensino de História? Como querer que os jovens se sintam atraídos por uma História ensinada que lhes parece estranha, alheia, estrangeira, em larga medida porque a História apreendida por seus professores durante o período de 
formação regular passou a quilômetros de distância dos debates e questões envolvendo seu ensino e/ou dos problemas da vida cotidiana de homens e mulheres?

O que fazer para promover a conexão entre a História acadêmica e a vida cotidiana de homens e mulheres? O que fazer para a História não continuar estrangeira à vida prática dos homens? Não há receitas, todos sabemos. Porém há um certo consenso de que as mudanças precisam acontecer e devem perpassar o currículo de História. Nessa dimensão, as reflexões de Itamar Freitas são bastante elucidativas, quando ressalta:

\begin{abstract}
Pensar os currículos de história hoje - sobretudo no interior dos departamentos de história - é uma questão teórica e política muito importante e que não deve ficar relegada a um tópico de discussão de uma disciplina "didática" ministradas nos últimos períodos da licenciatura. Pensar currículos de história, sem nenhum exagero, é cultivar a manutenção da própria profissão que se quer ver reconhecida legalmente (FREITAS, 2013, p. 199).
\end{abstract}

Seguindo essas veredas, diversos professores/pesquisadores que problematizam o ensino vêm contribuindo com as discussões, apontando caminhos, apresentando propostas e relatos de experiência que envolvem uma infinidade de questões/problemas, que, se não resolvem a situação, contribuem para amenizar algumas tensões. São questões envolvendo o ensino de História e as novas tecnologias, o ensino de História e o tempo presente, o ensino de História e a formação docente, o ensino de História e o livro didático, o ensino de História e currículo, para citar alguns exemplos.

\title{
Livro didático e formação docente nas universidades federais no Nordeste: arquitetura do encastelamento
}

Como documentos institucionais, as Matrizes Curriculares analisadas constituem-se em uma espécie de "arquitetura" dos cursos e departamentos de História nas universidades do Brasil. Elas representam as digitais de um conjunto de discursos e práticas que caracterizam a forma de se fazer História como ciência em nossas universidades. Oferecem e dão a ler uma dada configuração que as licenciaturas em História adquiriram. Demonstram a concepção de História por meio de seus enunciados, suas disciplinas e ementários. Expressam 
suas filiações teóricas e conceituais. Revelam aproximações e distanciamentos com variadas acepções de História. Indicam o que consideram importante na formação dos graduados em História. Informam quais questões são obrigatórias para o profissional da área e quais questões são optativas. Revelam as diferentes acepções acerca de categorias analíticas que formam essa ciência, como "narrativa", "documento", "fato/acontecimento", para citar apenas alguns.

As Matrizes Curriculares indicam como a ciência histórica deve se compor em termos de seleção de conteúdos. Apontam o encadeamento das discussões e o sequenciamento dos conteúdos por períodos. Direcionam o que deve ser estudado e aprendido em cada etapa do processo de formação dos graduandos. É importante, todavia, ressaltar que não há uma relação de determinação entre o texto formal das Matrizes Curriculares e a sua exequibilidade. Há muitas variantes envolvidas. Muitas práticas desenvolvidas que não se encontram descritas nos documentos. Há muitos sujeitos atuando nesse palco e a encenação não segue a determinação irrestrita do roteiro oficial prescrito. Portanto essas matrizes precisam ser pensadas como vestígios, como indícios de um universo tenso, denso e complexo de questões em permanentes disputas e metamorfoses.

Vamos recorrer mais uma vez ao uso de metáforas para analisar alguns indícios que representam certas práticas pelas quais a ciência histórica vem se configurando, de maneira mais específica no que tange ao ensino de História na relação entre formação docente e livro didático. Agora imaginemos um alfaiate que faça um curso em que não aprenda a lidar com a tesoura. Ou uma costureira que não aprenda a manusear as agulhas, sendo essas o seu principal instrumento de ofício. Essas metáforas servem de analogia para pensarmos nos primeiros vestígios que emergem de uma pesquisa que iniciei recentemente.

Estou desenvolvendo uma pesquisa para analisar as Matrizes Curriculares ou Projeto Político Curricular - também denominado, em alguns casos, Projeto Político Pedagógico - dos cursos de graduação em História oferecidos nas universidades federais da Região Nordeste do Brasil. O principal objetivo é analisar se o livro didático de História é objeto de problematização durante o processo de formação docente dos graduandos nas Matrizes Curriculares das instituições de ensino superior (IES) estudadas.

A pesquisa encontra-se em desenvolvimento. Até o momento, fiz o levantamento em 14 matrizes curriculares de diferentes instituições, e os primeiros sinais que começam a emergir do material estudado apontam para uma configuração que serve de indício para entendermos como o livro didático é apreendido nas Matrizes Curriculares. Por conseguinte, também é possível compreender como o ensino da História é apresentado e representado nesses espaços de formação inicial. 
Se nossa forma de agir, como atores políticos, é resultante da maneira como apreendemos e interpretamos o tempo, um olhar atento para as Matrizes Curriculares dos cursos em que atuamos demonstra uma questão que merece atenção especial. Tal situação, do meu ponto de vista, representa um "presente condensado" que tensiona, questiona e desafia algumas práticas da atividade historiadora, sobretudo aquelas ligadas à atuação docente, como professores/ formadores, professores responsáveis pela formação de outros professores.

Virou palavra de ordem, na configuração presente do nosso tempo, que os livros didáticos precisam ser transformados em objeto de investigação na educação básica e que os professores necessitam transformá-los e usá-los como objeto de pesquisa em sala de aula. Esse discurso ressalta ainda que não se pode usá-los como depositário de verdades absolutas, e que se precisa usar o livro didático como um recurso a mais e não como única ferramenta de trabalho. Essas expressões, bastante evocadas nos espaços acadêmicos, viraram jargões; transformaram-se em ecos vazios lançados ao vento. O problema não será resolvido apenas apontando que os professores devem ressignificar os usos que fazem dos livros didáticos. Que condições práticas os professores têm para promover tamanha mudança? Que disciplinas (no plural), durante o período de formação regular, oferecem as condições para experienciar essa problematização entre os formandos?

Irei apresentar uma amostragem parcial de como estão estruturadas algumas matrizes curriculares das licenciaturas em História em algumas universidades públicas federais, no que diz respeito à problematização do principal instrumento de trabalho dos profissionais que estão sendo formados nessas áreas e instituições, qual seja, o livro didático.

De acordo com o relatório do perfil curricular de 2013 do curso de licenciatura em História da Universidade Federal de Pernambuco (UFPE), não há nenhuma disciplina que se encarregue de discutir o livro didático na atuação da docência da educação básica. São oferecidas 75 disciplinas - 35 obrigatórias e 40 eletivas - e nenhuma delas é voltada para problematizar o livro didático.

A UFPE oferta duas disciplinas obrigatórias sobre o ensino de História que, acordo com suas ementas, não se propõem a problematizar o livro didático: Metodologia do Ensino de História I e Metodologia do Ensino de História II. Esses componentes, respectivamente, propõem-se a estudar:

7 Estou dialogando com o conceito apresentado pelo historiador Reinhart Koselleck para quem o presente condensado é o presente que experiencia diversas temporalidades, constituindo-se simultaneamente como presente passado, presente presente e presente futuro. Para ampliar as discussões, consultar Koselleck (2014). 
A História como disciplina escolar, os fundamentos teórico-metodológicos do Ensino da História no Ensino fundamental ( $5^{\mathrm{a}}$ a $8^{\mathrm{a}}$ séries), seus conceitos fundamentais e modelos de Ensino e aprendizagem.

Analisa pesquisas sobre o Ensino da História, mapeando as diferentes temáticas estudadas, e discutindo seus principais resultados, com destaque para as investigações sobre as diretrizes curriculares da disciplina. Promove experiências didáticas que sugerem alternativas para a prática docente. Analisa o uso de novas linguagens e tecnologias aplicadas ao Ensino da disciplina. Discute a avaliação no Ensino e na aprendizagem da História. (Perfil Curricular-UFPE, 2013, p. 4. Acesso em 29 de dezembro de 2016).

Essa situação não é exceção. Parece ser regra entre a maioria das instituições até o momento pesquisadas. Na Matriz Curricular da Universidade Federal de Alagoas (Ufal), campus Maceió, também não há nenhum componente curricular obrigatório que se encarregue das discussões acerca do livro didático entre as 45 disciplinas obrigatórias. Situação análoga à da Universidade Federal da Bahia (UFBA).

Os professores formados no curso de licenciatura em História da Universidade Federal de Campina Grande (UFCG), no estado da Paraíba (campus sede) também concluem sua graduação sem nenhuma discussão sobre o livro didático, de acordo com o organograma de disciplinas disponíveis no site dessa instituição. ${ }^{8}$ Os professores formados na Universidade Federal da Paraíba (UFPB) também não dispõem de disciplinas obrigatórias, no quadro oferecido por sua Matriz Curricular, que envolvam a reflexão desse objeto de análise. A mesma situação encontramos na Matriz Curricular da Universidade Federal do Maranhão (UFMA), que mesmo incluindo em todas as suas disciplinas um objetivo de estudo, por meio do qual propõe um diálogo com a educação básica e às questões ambientais, não aparece nenhuma menção ao livro didático como instrumento de trabalho dos futuros professores.

Entretanto há algumas universidades que, mesmo não ofertando uma disciplina que se encarregue especificamente do estudo acerca do livro didático, esse objeto de análise é inserido em alguns componentes curriculares voltados para a problematização sobre o ensino de História. A Universidade Federal Rural de Pernambuco (UFRPE) insere-se nesse movimento. Segundo o Projeto Pedagógico Curricular (PPC) do curso de História dessa instituição, há uma disciplina ofertada no sétimo período, denominada Metodologia do Ensino de

8 No site do departamento de História da UFCG, não há disponível a matriz curricular nem os ementários. O único documento disponível é o fluxograma com as disciplinas por cada período do curso. 
História II. Essa disciplina obrigatória, com 60 horas/aula, alocada na área de "Disciplinas Pedagógicas", tem como pré-requisito a disciplina Metodologia do Ensino de História I, disponível no sexto período da Matriz Curricular. De acordo com a ementa, objetiva estudar um conjunto de questões que envolvem o ensino de História, entre elas o livro didático. Nessa dimensão, esse componente propõe-se a fazer a seguinte análise:

[...] construção de conhecimentos básicos para aplicação de técnicas, recursos didáticos no Ensino de História. $\underline{\mathrm{O} \text { livro didático nas aulas de }}$ História. $\mathrm{O}$ uso de documentos impressos e audiovisuais como suporte didático do Ensino de História. O uso de literatura na História escolar. $\mathrm{O}$ uso de jogos didáticos no Ensino de História. Produção de material didático. (PPC, UFRPE, 2013, p. 91. Acesso em 15 de junho de 2016. Grifos meus).

A Universidade Federal do Ceará (UFC) também acompanha esse movimento. Entre suas disciplinas obrigatórias quatro delas fazem menção aos livros ou materiais didáticos como objeto de análise em suas ementas. Entre os componentes denominados de "Oficinas de História" três deles propõem-se a analisar os materiais didáticos entre seus objetivos. Também no "Estágio Supervisionado I" há menção ao livro didático como objeto de estudo.

A Universidade Federal do Recôncavo da Bahia (UFRB), por sua vez, oferece uma disciplina denominada Ensino de História. Trata-se de um componente obrigatório com 68 horas/aula que, de acordo com a ementa disponível na Matriz Curricular, dispõe-se a analisar:

Relações entre as inovações vivenciadas pela historiografia mundial e brasileira com a História escrita e divulgada nos Ensinos Fundamental e Médio. Articulação da produção do conhecimento histórico e de sua transposição para o Ensino da disciplina. Análise dos conteúdos e temáticas presentes nos currículos escolares de História e dos conteúdos presentes em livros didáticos. (PPC, UFRB, 2014, p. 1. Acesso em 28 de dezembro de 2016. Grifos meus).

Uma situação análoga é encontrada na Universidade Federal do Piauí (UFPI) e na Universidade Federal de Sergipe (UFS). Na UFPI, o livro didático só aparece como um dos objetivos de estudo no Estágio Supervisionado I. Na 
Matriz Curricular da UFS, por sua vez, o livro didático, como objeto de interesse, aparece na ementa da disciplina Didática e Metodologia do Ensino de História, componente curricular obrigatório com 60 horas/aula. De acordo com sua ementa, as discussões são direcionadas para compreender:

Relação Teoria e Prática de Ensino; Didática da História como uma subárea da História; objetivos do Ensino de História; consciência Histórica e modelos de currículos de História; Princípios básicos do Ensino de História; Transversalidade e Ensino de História; PCN e Ensino de História; PNLD e a escolha do Livro Didático; Diferentes fontes e linguagens no Ensino de História. (Departamento de História - UFS. Ementa, p. 01. Acesso em 29 de dezembro de 2016. Grifos meus). ${ }^{9}$

As disciplinas ofertadas nos cursos de licenciatura duram, em média, quatro meses. Os componentes nas Matrizes Curriculares pesquisadas apresentam, em média, cinco objetivos ou temáticas de estudo ligados ao ensino de História, entre eles, o livro didático. Se usarmos como parâmetro o tempo de execução de uma disciplina, tem-se aí menos um mês para debater todo o universo de questões que envolvem o livro didático.

A Universidade Federal do Rio Grande do Norte (UFRN), campus sede, não dispõe de nenhuma disciplina obrigatória voltada para problematizar o livro didático. Entretanto a Matriz Curricular do curso dessa instituição oferece um componente optativo destinado, especificamente, às problematizações que envolvem o livro didático, qual seja, Ensino de História e Materiais Didáticos. Segundo sua ementa, a disciplina propõe-se a analisar:

A História dos materiais didáticos utilizados no Ensino de História (séculos XIX, XX e XXI). O Ensino de História nas aulas radiofônicas. Especificidades da História do livro didático. A utilização de expressões culturais (teatro, música, cinema) no Ensino de História. A pesquisa Histórica e o conhecimento histórico na produção de materiais didáticos. A transformação de documentos diversos em materiais didáticos (Departamento de História - UFRN. Ementa, p. 1. Acesso em 30 de novembro de 2016).

9 Não foi localizado o PPC do curso no site da referida instituição e por essa razão não se encontra o ano de publicação. Todavia há ementas de todos os componentes curriculares separadas em abas específicas. Tal situação é análoga à encontrada na UFRN e na UFCG. 
Além desse componente, há mais duas disciplinas optativas também voltadas para as questões que envolvem o livro didático como objeto de análise: Ensino de História do Rio Grande do Norte, que, entre seus objetivos, propõe-se a problematizar aspectos da História desse estado nos livros didáticos, e Ensino de História e Mídias Digitais. Como disciplina optativa, na Matriz Curricular da UFBA aparece um componente ligado ao ensino de História que analise entre seus objetivos, os livros didáticos.

\section{Considerações finais}

Das 14 Matrizes Curriculares pesquisadas até o momento, não há uma instituição que ofereça uma disciplina obrigatória que se encarregue especificamente de problematizar o livro didático. Ainda usando como critério os componentes curriculares obrigatórios, temos apenas as Matrizes Curriculares da UFC, UFRPE, UFRB, UFAL/Sertão, UFS e UFCG/Cajazeiras como instituições que inserem o livro didático entre os objetivos a que se destinam algumas disciplinas voltadas para o ensino de História. Em termos de disciplinas optativas, o cenário também não é animador. Temos apenas a UFRN e a UFBA Sede como já mencionado.

As Matrizes Curriculares são projetos fabricados com lentes interpretativas forjadas nas lutas políticas das experiências temporais. Nesse sentido, não são projetos estáticos. Com ritmos e direções variadas, expressam, revelam e se constituem como uma estratégia política de produzir ciência. Por conseguinte, selecionam, inserem, silenciam, recortam e nomeiam, em diferentes momentos, o que consideram legítimo e indispensável para sua construção. As Matrizes Curriculares das licenciaturas em História são, também, projetos políticos por meio dos quais se formam professores, ou seja, são espaços de formação de formadores. Portanto, se reconhecermos que a História como Ciência precisa ressignificar-se e repensar suas relações com a sociedade e com os anseios da vida cotidiana de homens e mulheres que vivem fora do castelo, um dos caminhos possíveis talvez seja colocar seu ensino - e, portanto, a formação docente - como lugar central de problematização, como objeto de relevante preocupação na investigação historiográfica.

O ensino ainda continua sendo o caminho legal, formal e institucional por meio do qual a História como disciplina escolar chega a todos os municípios do Brasil onde tenha uma escola com educação básica. E, como já mencionado, se há a constatação de que a História precisa mudar, é pelo currículo que se 
deve iniciar, refazendo e ressignificando as Matrizes Curriculares. Em última instância, é por meio desses documentos produzidos nos departamentos de História que estarão sendo formados os professores e professoras que atuarão no ensino da História em escolas públicas e privadas no ensino fundamental, já que, no ensino médio, sua prática foi amputada pela Lei 13.415. Assim, antes que ocorra o mesmo em toda a educação básica e, por extensão, com os cursos de licenciaturas, é aconselhável que fiquemos atentos, dispostos a estabelecer diálogos e promover as mudanças para ampliar as condições de possibilidade de prolongar a vida útil da História no tempo, como área de conhecimento e disciplina escolar.

Seria coerente que nós professores, que atuamos no ensino superior ou na educação básica, ao mesmo tempo em que preconizamos um discurso acerca da importância da manutenção da História como disciplina obrigatória no ensino médio, questionássemos qual lugar ocupa o ensino da História no departamento da universidade em que atuamos ou na escola onde lecionamos. Se o ensino de História encontra-se, no momento, em uma encruzilhada, e se já foi decretada sua sentença de morte no ensino médio, por meio da Lei n. ${ }^{\circ} 13.415 / 2017$, isso ocorre, também, porque esse ensino nunca foi prioridade entre uma larga parcela de historiadores e/ou departamentos de História das universidades brasileiras. Não podemos negar que há exceções. Mas são, exatamente, exceções. Se o ensino da História, hoje, encontra-se encurralado, nós que atuamos como profissionais desse campo de conhecimento temos nossa parcela de responsabilidade.

\section{REFERÊNCIAS}

ASSOCIAÇÃO NACIONAL DE HISTÓRIA - ANPUH-Brasil. Contra a exclusão da história como disciplina obrigatória no ensino médio. 2015. Disponível em: $<\mathrm{http}: / /$ site.anpuh.org/index.php/2015-01-20-00-01-55/noticias2/noticias-destaque/item/4032-contra-a-exclusao-da-historia-como-disciplina-obrigatoria-no-ensino-medio $>$. Acesso em: 10 mar. 2017.

BITTENCOURT, Circe Maria Fernandes. Ensino de história: fundamentos e métodos. São Paulo: Cortez, 2009.

BURKE, Peter (Org.). A escrita da história. Novas perspectivas. São Paulo: Editora da UNESP, 1992.

CARDOSO, Omar. Para uma definição de didática da História. Revista Brasileira de História. São Paulo, v. 28, n. 55, 2008. 
CERRI, Luis Fernando. Didática da História: uma leitura teórica sobre a História na prática. Revista de História Regional, 15(2): 264-278, 2010.

CERTEAU, Michel de. A escrita da história. Rio de Janeiro: Forense Universitária, 2007.

CHARTIER, Roger. A História Hoje: dúvidas, desafios e propostas. Estudos Históricos, Rio de Janeiro, 13, 1994.

CONGRESSO NACIONAL. Reforma do Ensino Médio. Disponível em: <http://congressoemfoco.uol.com.br/noticias/reforma-do-ensino-medio-veja-como-cada-deputado-votou/>. Acesso em: 26 jan. 2017.

DOSSE, François. A História. São Paulo: Editora UNESP, 2012.

FERREIRA, Marieta de Moraes; FRANCO, Renato. Desafios do ensino de História. Estudos Históricos, Rio de Janeiro, v. 21, n. 41, p. 79-93, 2008.

FONSECA, Selva Guimarães. A formação de professores de história no Brasil: perspectivas desafiadoras de nosso tempo. In: ZAMBONI, Ernesta; FONSECA, Selva Guimarães (Orgs.). Espaço de formação do professor de história. Campinas, SP: Papirus, 2008.

FONSECA, Selva Guimarães. Didática e prática de ensino de história. Campinas, SP: Papirus, 2003.

FREITAS, Itamar. Reformas educacionais e os currículos nacionais para o Ensino de História no Brasil Republicano (1931/2009). Cadernos de História da Educação, Uberlândia: UFU, v. 12, n. 1, 2013.

HARTOG, François. Regimes de Historicidades: presentismo e experiências do tempo. Belo Horizonte: Autêntica, 2014.

HARTOG, François. Tempo e Patrimônio. Varia História, Belo Horizonte, v. 22, n. 36, jul./dez. 2006.

KOSELLECK, Reinhart. Futuro Passado: contribuição à semântica dos tempos históricos. Rio de Janeiro: Contraponto/Editora PUC-Rio, 2006.

MATHIAS, Carlos Leonardo Kelmer. O ensino de História no Brasil: contextualização e abordagem historiográfica. História Unisinos, São Leopoldo, 15(1):40-49, jan./abr. 2011.

MONTEIRO, Ana Maria. Professores de história: entre saberes e práticas. Rio de Janeiro: Mauad X, 2007.

MONTEIRO, Ana Maria; GASPARELLO, Arlette Medeiros; MAGALHÃES, Marcelo de Souza (Org.). Ensino de história: sujeitos, saberes e práticas. Rio de Janeiro: Mauad X, 2007.

MONTENEGRO, Antonio Torres. História, Metodologia, Memória. São Paulo: Contexto, 2010 .

MOREIRA, Antônio Flávio Barbosa; SILVA, Tomaz Tadeu da. Currículo, cultura e sociedade. São Paulo: Cortez, 2000. 
NORA, Pierre. Entre memória e história: a problemática dos lugares. Revista Projeto História, São Paulo, n. 10, dez 1993.

OLIVEIRA, Margarida Dias de; FREITAS, Itamar. Desafios da formação inicial para a docência em história. Revista História Hoje, v. 2, n. 3, p. 131-147, 2013.

RICCI, Claudia Sapag. Historiador e/ou professor de história: a formação nos cursos de graduação de História. Revista História Hoje, v. 4, n. 7, p. 107-135, 2015.

RICEUR, Paul. O passado tinha um futuro. In: MORIN, Edgar (Org.). A religação dos saberes: o desafio do século XXI. Rio de Janeiro: Bertrand Brasil, 2012.

RÜSEN, Jörn. Razão Histórica. Teoria da história: os fundamentos da ciência histórica. Tradução: Estevão de Rezende Martins. Brasília, Editora da Universidade de Brasília, 2010 .

RÜSEN, Jörn. Didática da História: passado, presente e perspectiva a partir do caso alemão. In: SCHMIDT, Maria Auxiliadora, BARCA, Isabel; MARTINS, Estevão de Rezende (Org.). Jörn Rüsen e o Ensino de História. Curitiba: Ed. UFPR, 2011.

SADDI, Rafael. Didática da História como subdisciplina da Ciência Histórica. História \& Ensino, Londrina, v. 16, n.1, p.61-80, 2010.

SADDI, Rafael. O parafuso da Didática da História: o objeto de pesquisa e o campo de investigação de uma didática da história ampliada. Acta Scientiarum Education, Maringá, v. 34, n. 2, p. 211-220, 2012.

SCHMIDT, Maria Auxiliadora; BARCA, Isabel; MARTINS, Estevão de Rezende (Org.). Jörn Rüsen e o Ensino de História. Curitiba: Ed. UFPR, 2011.

UNIVERSIDADE FEDERAL DA BAHIA. Matriz Curricular do Curso de História. Disponível em: < https://alunoweb.ufba.br/SiacWWW/ListaDisciplinasEmentaPublico. do?cdCurso=386120\&nuPerCursoInicial=20161>. Acesso em: 28 dez. 2016.

UNIVERSIDADE FEDERAL DA PARAÍBA. Matriz Curricular do Curso de História. Disponível em: < http://www.cchla.ufpb.br/dhistoria/images/PPC_Coordenacao_atualizado.pdf>. Acesso em: 30 dez. 2016.

UNIVERSIDADE FEDERAL DE ALAGOAS. Matriz Curricular do Curso de História. Disponível em: <http://www.ufal.edu.br/estudante/graduacao/projetos-pedagogicos/campus-maceio/ppc-historia-bacharelado.pdf/at_download/file>. Acesso em: 29 dez. 2016.

UNIVERSIDADE FEDERAL DE CAMPINA GRANDE. Matriz Curricular do Curso de História. Disponível em: <http://analytics.lsd.ufcg.edu.br/cursosufcg/\#/historia_lic_d_cg/ requisitos>. Acesso em: 29 dez. 2016.

UNIVERSIDADE FEDERAL DE CAMPINA GRANDE. Matriz Curricular do Curso de História - CERES. Disponível em: <http://www.cfp.ufcg.edu.br/historia/conteudo/ projeto-pedagogico-historia.pdf>. Acesso em: 29 dez. 2016. 
UNIVERSIDADE FEDERAL DE PERNAMBUCO. Matriz Curricular do Curso de História. Disponível em: <https://www.ufpe.br/proacad/images/cursos_ufpe/historia_lic_1113.pdf>. Acesso em: 29 dez. 2016.

UNIVERSIDADE FEDERAL DE SERGIPE. Matriz Curricular do Curso de História. Disponível em: <https://www.sigaa.ufs.br/sigaa/public/curso/resumo_curriculo.jsf>. Acesso em: 30 dez. 2016.

UNIVERSIDADE FEDERAL DO CEARÁ. Matriz Curricular do Curso de História. Disponível em: < http://www.historia.ufc.br/admin/upload/Proj._Lice.pdf >.Acesso em: 29 dez. 2016.

UNIVERSIDADE FEDERAL DO MARANHÃO. Matriz Curricular do Curso de História. Disponível em: <http://www.ufma.br/portalUFMA/arquivo/Q3ppkb971ac4pcC. pdf>. Acesso em: 29 dez. 2016.

UNIVERSIDADE FEDERAL DO PIAUÍ. Matriz Curricular do Curso de História. Disponível em: $<$ http://leg.ufpi.br/subsiteFiles/cc/arquivos/files/historia_licen_noturno. pdf>. Acesso em: 30 dez. 2016.

UNIVERSIDADE FEDERAL DO RECÔNCAVO DA BAHIA. Matriz Curricular do Curso de História. Disponível em: <https://www.ufrb.edu.br/cahl/images/Ementas das_Disciplinas_Ofertadas_pelo_curso_de_Hist\%C3\%B3ria_-_Diurno.pdf $>$. Acesso em: 30 dez. $201 \overline{6}$.

UNIVERSIDADE FEDERAL DO RIO GRANDE DO NORTE. Matriz Curricular do Curso de História. Disponível em: < https://sigaa.ufrn.br/sigaa/link/public/curso/curriculo/100758>. Acesso em: 30 dez. 2016.

UNIVERSIDADE FEDERAL RURAL DE PERNAMBUCO. Matriz Curricular do Curso de História. Disponível em: <http://docplayer.com.br/14157878-Projeto-pedagogico-de-curso-ppc.html> Acesso em: 30 dez. 2016.

Texto recebido em 24 de junho de 2018.

Texto aprovado em 20 de julho de 2018. 